\title{
Genetic diversity analysis of okra (Abelmoschus esculentus L.) by inter-simple sequence repeat (ISSR) markers
}

\author{
C.Y. Yuan ${ }^{1 *}$, C. Zhang ${ }^{1 *}$, P. Wang ${ }^{1}$, S. Hu${ }^{1}$, H.P. Chang ${ }^{1}$, W.J. Xiao ${ }^{1}$, \\ X.T. Lu' ${ }^{1}$, S.B. Jiang ${ }^{3}$, J.Z. Ye ${ }^{2}$ and X.H. Guo ${ }^{1}$ \\ ${ }^{1}$ School of Biology, Hunan University, Changsha, China \\ ${ }^{2}$ College of Electrical and Information Engineering, Hunan University, \\ Changsha, China \\ ${ }^{3}$ Department of Pharmaceutics, University of Florida, Orlando, FL, USA \\ *These authors contributed equally to this study. \\ Corresponding authors: J.Z. Ye/X.H. Guo \\ E-mail: yjz@hnu.edu.cn / gxh@hnu.edu.cn
}

Genet. Mol. Res. 13 (2): 3165-3175 (2014)

Received January 9, 2014

Accepted April 3, 2014

Published April 25, 2014

DOI http://dx.doi.org/10.4238/2014.April.25.1

\begin{abstract}
Okra (Abelmoschus esculentus L.) is not only a nutrientrich vegetable but also an important medicinal herb. Inter-simple sequence repeat (ISSR) markers were employed to investigate the genetic diversity and differentiation of 24 okra genotypes. In this study, the PCR products were separated by electrophoresis on $8 \%$ nondenaturing polyacrylamide gel and visualized by silver staining. The 22 ISSR primers produced 289 amplified DNA fragments, and 145 (50\%) fragments were polymorphic. The 289 markers were used to construct the dendrogram based on the unweighted pair-group method with arithmetic average (UPGMA) cluster analysis. The dendrogram indicated that 24 okras were clustered into 4 geographically distinct groups. The average polymorphism information content (PIC) was 0.531929 , which showed that the majority of primers were informative. The high values of allele frequency, genetic diversity, and heterozygosity showed that primer-sample combinations produced measurable fragments. The mean distances ranged from 0.045455 to
\end{abstract}


0.454545. The dendrogram indicated that the ISSR markers succeeded in distinguishing most of the 24 varieties in relation to their genetic backgrounds and geographical origins.

Key words: Okra; Inter-simple sequence repeat (ISSR); Genetic diversity

\section{INTRODUCTION}

Okra, a dicotyledoneae ephemeral herb, belongs to the Mallow family. It is valued for its edible green seed pods. The geographical origin of okra is disputed, with supporters of South Asian, Ethiopian, and West African origins. The plant is cultivated in tropical, subtropical, and warm temperate regions around the world. Currently, okra are cultivated and distributed throughout the world. China is a large agricultural nation with a long history of okra cultivation (de Sousa Ferreira Soares et al., 2012), with a more than 100-year history of planting in Pingxiang, Jiangxi Province. Okra evolved from potatoes and the spicy pepper a hundred years ago. It was considered a minor crop until more attention was paid to its recent genetic improvements (Schafleitner et al., 2013), especially its rapid growth cycle, easy cultivation, resistance to pests, high yield, and high nutritional value (Calisir et al., 2005). The whole body of the okra is a treasure. The leaves and seeds are considered a valuable traditional medicine (Gul et al., 2011). Okra seeds contain abundant mineral elements, including iron, potassium, calcium, and manganese. It is also an oil and protein source, which can be used as a coffee additive (i.e., in place of drinking coffee). The fruit is a popular vegetable, which was supplied in the 2008 Beijing Olympic Games because it contains abundant vitamins, pectin, and minerals (Oyelade et al., 2003). The big and beautiful flowers of okra can be used as an ornamental plant. Okra is an allopolyploid plant with considerable variation in its chromosome number and ploidy level. The chromosome number ranges from 56 for Abelmoschus angulosus to 200 for A. caillei, an amphipolyploid between A. esculentus and A. caillei (Ford, 1938; Siemonsma, 1982).

The availability of a variety of DNA marker systems such as amplified fragment length polymorphism (AFLP), random amplified polymorphic DNA (RAPD), and simple sequence repeat (SSR) (Gupta and Varshney, 2000) are limited by the low reproducibility of RAPD, high cost of AFLP, and the need to know the flanking sequences to develop species-specific primers for SSR polymorphism (Reddy et al., 2002). Inter-simple sequence repeat (ISSR) was employed to investigate genetic diversity and differentiation. ISSR has a few advantages because ISSR primers anneal directly to simple sequence repeats and, thus, unlike SSR markers, no prior knowledge of a target sequence is required (Wang et al., 2012).

ISSR-polymerase chain reaction (PCR) is an alternative strategy that has been devised to reduce the time invested in microsatellite isolation and significantly increase yield (Babaei et al., 2012). In particular, ISSR markers allow more stringent annealing temperatures and reveal more polymorphic fragments. They can be highly variable within a species. The cost of the ISSR analysis is relatively lower than that of AFLP (Esselman et al., 1999) and displays acceptable reproducibility. Therefore, it is widely used in current studies of population genetics [e.g., bermudagrass (Farsani et al., 2012), Houttuynia cordata (Wei and Wu, 2012), and cultivated bromeliad (Zhang et al. 2012)]. In this paper, ISSR markers were used to analyze the genetic diversity and genetic structure of okra populations from the different regions in China. The population-level genetic diversity of okra was analyzed in the present study for the first time to determine the genetic differentiation between populations from the 
different regions in China. It will provide invaluable information for future okra conservation and management programs.

\section{MATERIAL AND METHODS}

\section{Total DNA extraction}

Okra leaves were collected from different locations in China. Genomic DNA was extracted from $0.5 \mathrm{~g}$ fresh leaves following the improved CTAB protocol (Jie et al., 2008). The DNA quality was determined using $1.0 \%$ agarose gels. The purified genomic DNA was quantified using a BioRad SmartSpec 3000 UV-Vis Spectrophotometer.

\section{ISSR PCR amplification}

ISSR markers were produced by PCR using the genomic DNA and ISSR primers. PCRs were conducted using 22 primers (Table 1 ) to characterize the 24 okra varieties. The $20-\mu \mathrm{L}$ mixture contained 10 ng template DNA, $2.0 \mu \mathrm{L}$ 10X PCR buffer, $1.8 \mathrm{mM} \mathrm{MgCl}_{2}, 0.1 \mathrm{mM}$ dNTPs (TaKaRa, Dalian, China), $2 \%$ formamide, $100 \mathrm{nM}$ of each primer, $1.5 \mathrm{U}$ Taq polymerase (TaKaRa, Dalian, China), and double-distilled water. Amplifications were performed using an ABI 2720 Thermal Cycler (Applied Biosystems, USA) with the following PCR program: 5 min of initial denaturing at $94^{\circ} \mathrm{C}, 40$ cycles of $94^{\circ} \mathrm{C}$ for $45 \mathrm{~s}, 1 \mathrm{~min}$ for annealing at the primer-specific melting temperature, and $72^{\circ} \mathrm{C}$ for $90 \mathrm{~s}$, followed by a final extension of $5 \mathrm{~min}$ at $72^{\circ} \mathrm{C}$. First, the PCR products were analyzed by electrophoresis on $2.0 \%$ agarose gel with $0.5 \mathrm{X}$ TBE buffer. Then, the PCR products were electrophoretically separated using $8.0 \%$ nondenaturing polyacrylamide gels buffered with $0.5 \mathrm{X} \mathrm{TBE}$, run at $250 \mathrm{~V}$ (constant) for $2.5 \mathrm{~h}$, and visualized by silver staining (Mortz et al., 2001). A 100-bp DNA ladder was used as a size marker.

Table 1. ISSR primers with annealing temperature $(\mathrm{Tm})$ used in this study and the amplified results as the number of total bands (TB), number of polymorphic bands (PB), and \% of polymorphic bands (PPB).

\begin{tabular}{|c|c|c|c|c|c|}
\hline Primer & Sequence $5^{\prime}-3^{\prime}$ & $\operatorname{Tm}\left({ }^{\circ} \mathrm{C}\right)$ & TB & PB & PPB $(\%)$ \\
\hline 809 & AGAGAGAGAGAGAGAGG & 47 & 12 & 2 & 17 \\
\hline 811 & GAGAGAGAGAGAGAGAC & 47 & 21 & 10 & 47 \\
\hline 817 & CACACACACACACACAA & 45 & 10 & 6 & 60 \\
\hline 818 & CACACACACACACACAG & 47 & 15 & 11 & 73 \\
\hline 823 & TCTCTCТСТСТСТСТCC & 47 & 7 & 3 & 43 \\
\hline 825 & ACACACACACACACACT & 45 & 10 & 4 & 40 \\
\hline 829 & TGTGTGTGTGTGTGTGC & 47 & 9 & 2 & 22 \\
\hline 830 & TGTGTGTGTGTGTGTGG & 47 & 7 & 3 & 43 \\
\hline 834 & AGAGAGAGAGAGAGAGCT & 47 & 12 & 7 & 58 \\
\hline 835 & AGAGAGAGAGAGAGAGCC & 49 & 7 & 3 & 43 \\
\hline 840 & GAGAGAGAGAGAGAGACT & 49 & 16 & 10 & 63 \\
\hline 841 & GAGAGAGAGAGAGAGACC & 49 & 13 & 3 & 23 \\
\hline 842 & GAGAGAGAGAGAGAGATG & 49 & 15 & 9 & 60 \\
\hline 846 & CACACACACACACACAAT & 49 & 14 & 13 & 93 \\
\hline 847 & CACACACACACACACAAC & 51 & 20 & 6 & 30 \\
\hline 848 & CACACACACACACACAAG & 51 & 21 & 20 & 95 \\
\hline 855 & ACACACACACACACACCT & 49 & 9 & 7 & 78 \\
\hline 857 & ACACACACACACACACCG & 49 & 17 & 14 & 82 \\
\hline 884 & ACTAGAGAGAGAGAGAG & 47 & 18 & 2 & 11 \\
\hline 887 & GCATCTCTCTCTCTCTC & 49 & 7 & 2 & 29 \\
\hline 889 & ACTACACACACACACAC & 49 & 14 & 5 & 36 \\
\hline 891 & ACTTGTGTGTGTGTGTG & 49 & 15 & 3 & 20 \\
\hline Average & & & 13 & 7 & 50 \\
\hline Total & & & 289 & 145 & \\
\hline
\end{tabular}




\section{Data analysis}

All ISSR bands were scored as present (1) or absent (0). The obtained genetic distance matrix was used to perform the cluster analysis and construct the unweighted pairgroup method with arithmetic average (UPGMA) dendrogram using the PowerMarker software (Liu and Muse 2005). We used the PowerMarker software to calculate polymorphism information content (PIC), allele frequency, genetic diversity, genetic distance, and heterozygosity for each primer. The principal coordinated analysis (PCoA) was performed with the modules DCENTER and EIGEN implemented in NTSYS-pc, and the 2 principal coordinates were used to visualize the dispersion of accessions in a two-dimensional array of eigenvectors. Bayesian assignment tests were applied to estimate the number of genetic clusters and evaluate the degree of admixture among them using Structure v2 (Pritchard et al., 2000). Structure was run with a "burn-in" setting of 100,000 followed by 20,000 MCMC iterations using the admixture model with sampling localities as prior population assignment and allelic frequencies correlated among populations. Ten runs were performed for each value for $K$ ranging from 2 to 7. The most likely value for $K$ was calculated with STRUCTURE HARVESTER (Earl and vonHoldt, 2012) using the statistic $K$, which represents the greatest rate of change between each subsequent $K$ value (Evanno et al., 2005).

\section{RESULTS}

\section{ISSR polymorphism}

The 22 selected ISSR primers produced 289 fragments, with an average of 13 bands per primer. There were 145 polymorphic fragments ranging from 200 to $1500 \mathrm{bp}$. The number of bands by each primer ranged from 7 to 21 , with an average of 13 per primer (Table 1). At the population level, the percentage of polymorphic bands ranged from 11 to $23 \%$, with an average of $50 \%$. The banding pattern of genotypes generated by ISSR primers 847 and 848 are shown in Figure 1.

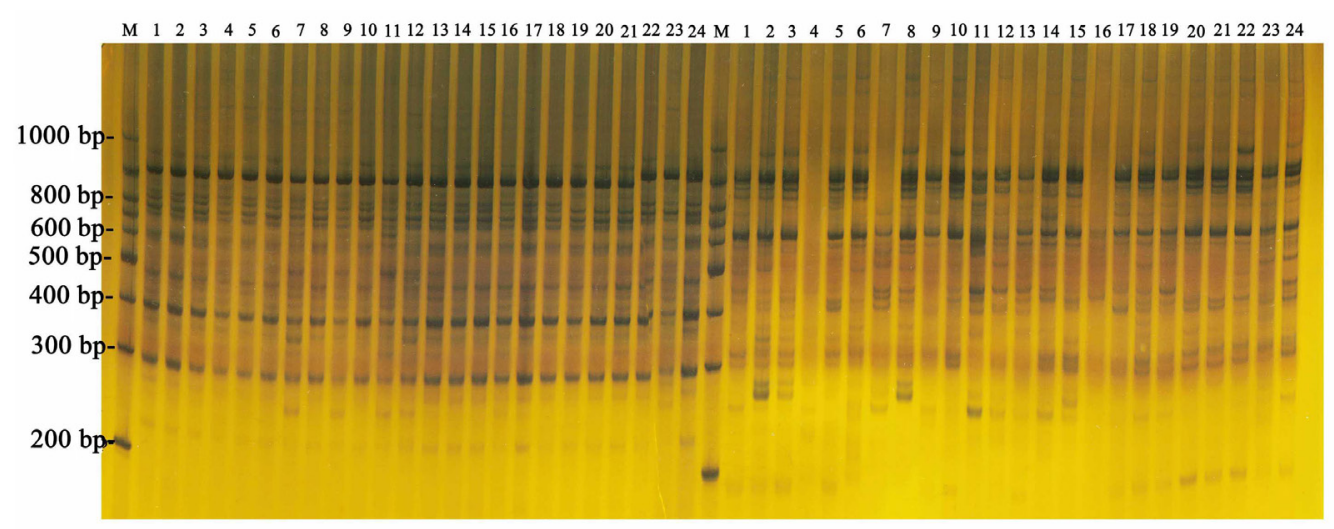

Figure 1. PAGE electrophoretic profiles of PCR products by using 847 and 848 ISSR primers for 24 okra varieties. Lanes 1-24 = WGS-1, WGS-2, WGS-5, WGS-3, WGS-4, PK-9, PK-10, WH-2, CS-1, CS-2, CS-4, CS-5, CS-3, WGS-7, WGS-6, PK-1, PK-2, WH-1, PK-4, PK-3, PK-7, PK-8, PK-6, and PK-5, respectively. 


\section{Genetic differentiation and relationships}

The neighbor-joining (NJ) dendrogram indicated that the 24 populations clustered into 4 geographically distinct groups (Figure 2). The populations (CS1-5) sampled from $\mathrm{Hu}-$ nan province formed Group I. Group II contained populations WH1 and WH2. Group III was comprised of populations from PK1 to PK10. The remaining populations (WGS1-7) formed Group IV. The above results were supported by correlation analysis between geographic and genetic distances for 24 populations of okra. The cluster results were entirely consistent with phenotype. Phenotype observations showed that PK-1, PK-2, PK-3, PK-4, PK-5, PK-6, PK-7, and PK-8 belonged to Hibiscus coccineus (Figure 3).



Figure 2. Neighbor-joining dendrogram based on genetic distances for the 24 populations of okra. 


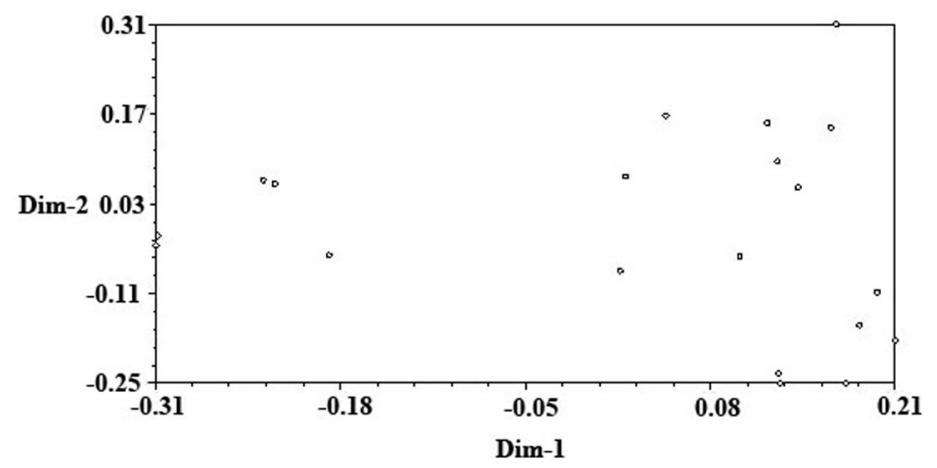

Figure 3. Two-dimensional matrix plot of the principal coordinate analysis showing associations among the cultivated bromeliad accessions.

We used the PowerMarker software to calculate the PIC value (i.e., 0.306659 to 0.694334 ; Table 2). The maximum and minimum values of allele frequency were 0.791666667 and 0.5 , respectively. The value of genetic diversity ranged from 0.34375 to 0.713541667 , and the highest value was found for primer 848 . We found that the value of heterozygosity ranged from 0.416666667 to 1 (Table 2). Genetic distances were calculated via PowerMarker, and the highest distance (0.454545) was obtained between WGS-3 and Hibiscus coccineus (Table $3)$. The genetic relationships among the investigated bromeliads were also investigated using PCoA. Two- and three-dimensional plots showing the dispersions of 24 okras are displayed in Figure 3; the sum of the eigenvalues was 4.538927. The STRUCTURE software was used in the ISSR admixture analysis (Figure 4). The highest likelihood of the data was obtained when samples were clustered into 4 groups $(K=4)$. These groupings were entirely consistent with those of the NJ clustering results.

Table 2. Allele frequency, genetic diversity, heterozygosity, and polymorphism information content (PIC) for each primer calculated by the PowerMarker software.

\begin{tabular}{llcllll}
\hline Marker & Major allele frequency & Genotype No. & $N_{\text {A }}$ & Gene diversity & Heterozygosity \\
\hline 809 & 0.520833333 & 3 & 3 & 0.565104167 & 0.958333333 & 0.474154 \\
811 & 0.5 & 7 & 8 & 0.677083333 & 1 & 0.638317 \\
817 & 0.541666667 & 5 & 5 & 0.638888889 & 0.916666667 & 0.596752 \\
818 & 0.5 & 6 & 7 & 0.692708333 & 1 & 0.661782 \\
823 & 0.5 & 3 & 4 & 0.660590278 & 1 & 0.611129 \\
825 & 0.625 & 5 & 5 & 0.563368056 & 0.75 & 0.526246 \\
829 & 0.5 & 2 & 3 & 0.61111111 & 1 & 0.535494 \\
830 & 0.5625 & 4 & 4 & 0.608506944 & 0.875 & 0.558403 \\
834 & 0.625 & 6 & 6 & 0.575520833 & 0.75 & 0.548282 \\
835 & 0.770833333 & 3 & 3 & 0.361979167 & 0.458333333 \\
840 & 0.729166667 & 3 & 5 & 0.439236111 & 0.541666667 & 0.309847 \\
841 & 0.791666667 & 5 & 3 & 0.34375 & 0.416666667 & 0.307969 \\
842 & 0.5 & 8 & 6 & 0.686631944 & 1 & 0.65228 \\
846 & 0.5 & 4 & 5 & 0.703125 & 1 & 0.678211 \\
847 & 0.5 & 10 & 11 & 0.603298611 & 1 & 0.52822 \\
848 & 0.5 & 4 & 4 & 0.713541667 & 1 & 0.694334 \\
855 & 0.5625 & 4 & 5 & 0.596354167 & 0.875 & 0.539014 \\
857 & 0.5 & 3 & 3 & 0.657986111 & 1 & 0.607522 \\
884 & 0.583333333 & 3 & 3 & 0.551215278 & 0.833333333 \\
887 & 0.791666667 & 4 & 4 & 0.350694444 & 0.416666667 & 0.475251 \\
889 & 0.520833333 & 2 & 3 & 0.605034722 & 0.958333333 \\
891 & 0.5 & 4.5 & 4.954545 & 0.582465278 & 1 & 0.322187 \\
Mean & 0.573863636 & & 0.581281566 & 0.852272727 & 0.53509 \\
\hline
\end{tabular}


Table 3. Genetic distance calculated for 24 okra populations by the PowerMarker software.

\begin{tabular}{|c|c|c|c|c|c|c|c|c|}
\hline OTU & PK-6 & PK-5 & $\mathrm{CS}-2$ & CS-1 & WH-2 & WGS-7 & WGS-6 & PK-1 \\
\hline PK-6 & 0 & 0 & 0.363636 & 0.386364 & 0.386364 & 0.363636 & 0.363636 & 0.227273 \\
\hline PK-5 & 0 & 0 & 0.363636 & 0.386364 & 0.386364 & 0.363636 & 0.363636 & 0.227273 \\
\hline CS-2 & 0.363636 & 0.363636 & 0 & 0.045455 & 0.318182 & 0.318182 & 0.318182 & 0.318182 \\
\hline CS-1 & 0.386364 & 0.386364 & 0.045455 & 0 & 0.340909 & 0.363636 & 0.363636 & 0.318182 \\
\hline WH-2 & 0.386364 & 0.386364 & 0.318182 & 0.340909 & 0 & 0.318182 & 0.318182 & 0.363636 \\
\hline WGS-7 & 0.363636 & 0.363636 & 0.318182 & 0.363636 & 0.318182 & 0 & 0 & 0.340909 \\
\hline WGS-6 & 0.363636 & 0.363636 & 0.318182 & 0.363636 & 0.318182 & 0 & 0 & 0.340909 \\
\hline PK-1 & 0.227273 & 0.227273 & 0.318182 & 0.318182 & 0.363636 & 0.340909 & 0.340909 & 0 \\
\hline PK-2 & 0.227273 & 0.227273 & 0.318182 & 0.318182 & 0.363636 & 0.340909 & 0.340909 & 0 \\
\hline WH-1 & 0.454545 & 0.454545 & 0.340909 & 0.363636 & 0.272727 & 0.227273 & 0.227273 & 0.318182 \\
\hline PK-4 & 0.204545 & 0.204545 & 0.409091 & 0.409091 & 0.363636 & 0.340909 & 0.340909 & 0.204545 \\
\hline PK-3 & 0.204545 & 0.204545 & 0.409091 & 0.409091 & 0.363636 & 0.340909 & 0.340909 & 0.204545 \\
\hline PK-7 & 0.045455 & 0.045455 & 0.363636 & 0.386364 & 0.363636 & 0.363636 & 0.363636 & 0.181818 \\
\hline Pk-8 & 0.045455 & 0.045455 & 0.363636 & 0.386364 & 0.363636 & 0.363636 & 0.363636 & 0.181818 \\
\hline CS-4 & 0.386364 & 0.386364 & 0.204545 & 0.204545 & 0.363636 & 0.295455 & 0.295455 & 0.340909 \\
\hline CS-5 & 0.386364 & 0.386364 & 0.204545 & 0.204545 & 0.363636 & 0.295455 & 0.295455 & 0.340909 \\
\hline CS-3 & 0.386364 & 0.386364 & 0.204545 & 0.204545 & 0.340909 & 0.272727 & 0.272727 & 0.340909 \\
\hline WGS-1 & 0.363636 & 0.363636 & 0.386364 & 0.409091 & 0.386364 & 0.272727 & 0.272727 & 0.363636 \\
\hline WGS-2 & 0.386364 & 0.386364 & 0.409091 & 0.431818 & 0.386364 & 0.318182 & 0.318182 & 0.431818 \\
\hline WGS-5 & 0.386364 & 0.386364 & 0.409091 & 0.431818 & 0.386364 & 0.318182 & 0.318182 & 0.431818 \\
\hline WGS-3 & 0.454545 & 0.454545 & 0.386364 & 0.363636 & 0.363636 & 0.318182 & 0.318182 & 0.431818 \\
\hline WGS-4 & 0.431818 & 0.431818 & 0.295455 & 0.318182 & 0.363636 & 0.295455 & 0.295455 & 0.409091 \\
\hline PK-9 & 0.295455 & 0.295455 & 0.318182 & 0.340909 & 0.318182 & 0.25 & 0.25 & 0.272727 \\
\hline PK-10 & 0.363636 & 0.363636 & 0.318182 & 0.363636 & 0.340909 & 0.25 & 0.25 & 0.340909 \\
\hline OTU & PK-2 & WH-1 & PK-4 & PK-3 & PK-7 & PK-8 & CS-4 & CS-5 \\
\hline PK-6 & 0.227273 & 0.454545 & 0.204545 & 0.204545 & 0.045455 & 0.045455 & 0.386364 & 0.386364 \\
\hline PK-5 & 0.227273 & 0.454545 & 0.204545 & 0.204545 & 0.045455 & 0.045455 & 0.386364 & 0.386364 \\
\hline CS-2 & 0.318182 & 0.340909 & 0.409091 & 0.409091 & 0.363636 & 0.363636 & 0.204545 & 0.204545 \\
\hline CS-1 & 0.318182 & 0.363636 & 0.409091 & 0.409091 & 0.386364 & 0.386364 & 0.204545 & 0.204545 \\
\hline WH-2 & 0.363636 & 0.272727 & 0.363636 & 0.363636 & 0.363636 & 0.363636 & 0.363636 & 0.363636 \\
\hline WGS-7 & 0.340909 & 0.227273 & 0.340909 & 0.340909 & 0.363636 & 0.363636 & 0.295455 & 0.295455 \\
\hline WGS-6 & 0.340909 & 0.227273 & 0.340909 & 0.340909 & 0.363636 & 0.363636 & 0.295455 & 0.295455 \\
\hline PK-1 & 0 & 0.318182 & 0.204545 & 0.204545 & 0.181818 & 0.181818 & 0.340909 & 0.340909 \\
\hline PK-2 & 0 & 0.318182 & 0.204545 & 0.204545 & 0.181818 & 0.181818 & 0.340909 & 0.340909 \\
\hline WH-1 & 0.318182 & 0 & 0.409091 & 0.409091 & 0.409091 & 0.409091 & 0.295455 & 0.295455 \\
\hline PK-4 & 0.204545 & 0.409091 & 0 & 0 & 0.181818 & 0.181818 & 0.431818 & 0.431818 \\
\hline PK-3 & 0.204545 & 0.409091 & 0 & 0 & 0.181818 & 0.181818 & 0.431818 & 0.431818 \\
\hline PK-7 & 0.181818 & 0.409091 & 0.181818 & 0.181818 & 0 & 0 & 0.409091 & 0.409091 \\
\hline Pk-8 & 0.181818 & 0.409091 & 0.181818 & 0.181818 & 0 & 0 & 0.409091 & 0.409091 \\
\hline CS-4 & 0.340909 & 0.295455 & 0.431818 & 0.431818 & 0.409091 & 0.409091 & 0 & 0 \\
\hline CS-5 & 0.340909 & 0.295455 & 0.431818 & 0.431818 & 0.409091 & 0.409091 & 0 & 0 \\
\hline CS-3 & 0.340909 & 0.272727 & 0.431818 & 0.431818 & 0.409091 & 0.409091 & 0.022727 & 0.022727 \\
\hline WGS-1 & 0.363636 & 0.363636 & 0.340909 & 0.340909 & 0.363636 & 0.363636 & 0.363636 & 0.363636 \\
\hline WGS-2 & 0.431818 & 0.386364 & 0.431818 & 0.431818 & 0.409091 & 0.409091 & 0.386364 & 0.386364 \\
\hline WGS-5 & 0.431818 & 0.386364 & 0.431818 & 0.431818 & 0.409091 & 0.409091 & 0.386364 & 0.386364 \\
\hline WGS-3 & 0.431818 & 0.318182 & 0.454545 & 0.454545 & 0.454545 & 0.454545 & 0.318182 & 0.318182 \\
\hline WGS-4 & 0.409091 & 0.318182 & 0.454545 & 0.454545 & 0.431818 & 0.431818 & 0.295455 & 0.295455 \\
\hline PK-9 & 0.272727 & 0.25 & 0.318182 & 0.318182 & 0.272727 & 0.272727 & 0.295455 & 0.295455 \\
\hline PK-10 & 0.340909 & 0.295455 & 0.386364 & 0.386364 & 0.340909 & 0.340909 & 0.318182 & 0.318182 \\
\hline
\end{tabular}

Continued on next page 
Table 3. Continued.

\begin{tabular}{|c|c|c|c|c|c|c|c|c|}
\hline OTU & $\mathrm{CS}-3$ & WGS-1 & WGS-2 & WGS-5 & WGS-3 & WGS-4 & PK-9 & PK-10 \\
\hline PK-6 & 0.386364 & 0.363636 & 0.386364 & 0.386364 & 0.454545 & 0.431818 & 0.295455 & 0.363636 \\
\hline PK-5 & 0.386364 & 0.363636 & 0.386364 & 0.386364 & 0.454545 & 0.431818 & 0.295455 & 0.363636 \\
\hline CS-2 & 0.204545 & 0.386364 & 0.409091 & 0.409091 & 0.386364 & 0.295455 & 0.318182 & 0.318182 \\
\hline CS-1 & 0.204545 & 0.409091 & 0.431818 & 0.431818 & 0.363636 & 0.318182 & 0.340909 & 0.363636 \\
\hline WH-2 & 0.340909 & 0.386364 & 0.386364 & 0.386364 & 0.363636 & 0.363636 & 0.318182 & 0.340909 \\
\hline WGS-7 & 0.272727 & 0.272727 & 0.318182 & 0.318182 & 0.318182 & 0.295455 & 0.25 & 0.25 \\
\hline WGS-6 & 0.272727 & 0.272727 & 0.318182 & 0.318182 & 0.318182 & 0.295455 & 0.25 & 0.25 \\
\hline PK-1 & 0.340909 & 0.363636 & 0.431818 & 0.431818 & 0.431818 & 0.409091 & 0.272727 & 0.340909 \\
\hline PK-2 & 0.340909 & 0.363636 & 0.431818 & 0.431818 & 0.431818 & 0.409091 & 0.272727 & 0.340909 \\
\hline WH-1 & 0.272727 & 0.363636 & 0.386364 & 0.386364 & 0.318182 & 0.318182 & 0.25 & 0.295455 \\
\hline PK-4 & 0.431818 & 0.340909 & 0.431818 & 0.431818 & 0.454545 & 0.454545 & 0.318182 & 0.386364 \\
\hline PK-3 & 0.431818 & 0.340909 & 0.431818 & 0.431818 & 0.454545 & 0.454545 & 0.318182 & 0.386364 \\
\hline PK-7 & 0.409091 & 0.363636 & 0.409091 & 0.409091 & 0.454545 & 0.431818 & 0.272727 & 0.340909 \\
\hline Pk-8 & 0.409091 & 0.363636 & 0.409091 & 0.409091 & 0.454545 & 0.431818 & 0.272727 & 0.340909 \\
\hline CS-4 & 0.022727 & 0.363636 & 0.386364 & 0.386364 & 0.318182 & 0.295455 & 0.295455 & 0.318182 \\
\hline CS-5 & 0.022727 & 0.363636 & 0.386364 & 0.386364 & 0.318182 & 0.295455 & 0.295455 & 0.318182 \\
\hline CS-3 & 0 & 0.363636 & 0.386364 & 0.386364 & 0.318182 & 0.295455 & 0.272727 & 0.295455 \\
\hline WGS-1 & 0.363636 & 0 & 0.295455 & 0.295455 & 0.340909 & 0.272727 & 0.272727 & 0.340909 \\
\hline WGS-2 & 0.386364 & 0.295455 & 0 & 0 & 0.295455 & 0.295455 & 0.363636 & 0.363636 \\
\hline WGS-5 & 0.386364 & 0.295455 & 0 & 0 & 0.295455 & 0.295455 & 0.363636 & 0.363636 \\
\hline WGS-3 & 0.318182 & 0.340909 & 0.295455 & 0.295455 & 0 & 0.204545 & 0.340909 & 0.363636 \\
\hline WGS-4 & 0.295455 & 0.272727 & 0.295455 & 0.295455 & 0.204545 & 0 & 0.318182 & 0.363636 \\
\hline PK-9 & 0.272727 & 0.272727 & 0.363636 & 0.363636 & 0.340909 & 0.318182 & 0 & 0.113636 \\
\hline PK-10 & 0.295455 & 0.340909 & 0.363636 & 0.363636 & 0.363636 & 0.363636 & 0.113636 & 0 \\
\hline
\end{tabular}

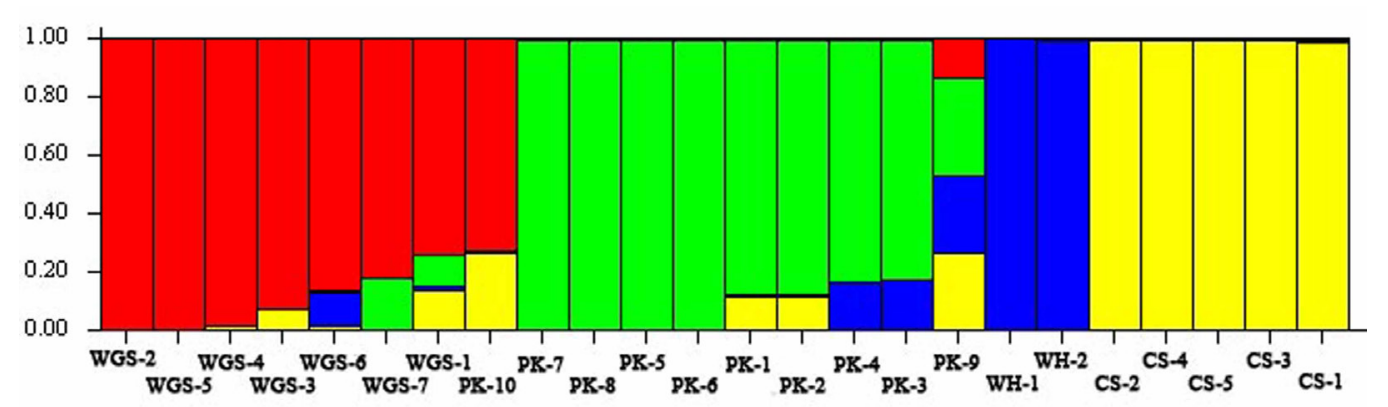

Figure 4. Genetic relationships among the 24 okra populations estimated using the STRUCTURE program based on ISSR data. The model with $\mathrm{K}=4$ showed the highest $\Delta K$ value.

\section{DISCUSSION}

Microsatellite markers are distinguished by a high degree of variability, thus making them powerful tools for population genetic analyses (Sethy et al., 2006). The common protocols used for the isolation of microsatellites are costly, time consuming, have low efficiency, and are laborious (Zane et al., 2002). To reduce the time invested in microsatellite isolation and significantly increase yield, ISSR-PCR can be used an alternative strategy. Furthermore, ISSR-PCR targets only those regions of the genome that are rich in microsatellite motifs. In plants, the construction of microsatellite markers has been proven to be effective with the $3^{\prime}$ 
and 5' anchored ISSR-PCR strategy in producing polymorphic loci for different species. This technique was highly successful, as over $86 \%$ of unique clones obtained contained internally located microsatellite motifs (in addition to those at the ends). The familiar protocols were used for agarose gels to separate the PCR products. It can certainly save both time and cost, however, a low percentage of polymorphic bands may be obtained. Nondenaturing polyacrylamide gels can produce clear bands and detect more polymorphic bands. In this study, the ISSR-PCR products were first visualized on a 1.5 or $2.0 \%$ agarose gel with ethidium bromide staining. Then, the PCR products were electrophoretically separated using $8.0 \%$ nondenaturing polyacrylamide gels, and the satisfactory experimental results were obtained.

As represented earlier, the okra, although widely distributed in Africa and all countries throughout the Caribbean, Europe, China, and Southeast Asia, has not been characterized with regard to genomic sequencing and microsatellite development. Therefore, these developed microsatellite markers for okra could promote future population genetic studies and breeding programs for this plant and related species. In the present study, the NJ dendrogram indicated that the 24 populations clustered into 4 geographically distinct groups (Figure 2). Phenotypic observations showed that PK-1, PK-2, PK-3, PK-4, PK-5, PK-6, PK-7, PK-8, PK-9, and PK10 belonged to Hibiscus coccineus. The results showed that PK-9 and PK-10 had a close genetic relationship. WGS-1, WGS-2, WGS-3, WGS-4, WGS-5, WGS-6, and WGS-7 belonged to Abelmoschus esculentus L., and, therefore, they clustered together to form Group IV.

Information on genetic diversity and population structure will be essential for providing further insight into the breeding history and genetic relationship of crop germplasm. In this study, $145(\sim 50 \%)$ of the 289 bands generated by the 22 ISSR primers were polymorphic. The results obtained in our study showed that the ISSR markers were successfully used for okra. The values of allele frequency, genetic diversity, and heterozygosity were high, which showed that the ISSR primers can produce some measurable fragments. The PIC provides an estimate of the discriminatory power of a marker to differentiate genotypes based on both the $N_{\mathrm{A}}$ expressed and the relative frequencies of alleles (Nagl et al., 2011). PIC was used to measure the genetic diversity in okra. High, medium, and low polymorphism is represented as PIC $>0.5,0.5>$ PIC $>0.25$, and PIC $<0.25$, respectively (Vaiman et al., 1994; Xie et al., 2010). The PIC value ranged from 0.306659 to 0.694334 , and the mean value in this study was 0.531929 , demonstrating that the primers could develop high polymorphism, which is useful for genetic variation of genotypes in this research. Genetic distances were examined for all pairwise comparisons between subpopulations. The mean distance ranged from 0.045455 to 0.454545 . The test showed high differences in the population of the 24 okras. The two- and three-dimensional graphs of accession differentiation were revealed by principal component analysis. This type of graphical illustration enables an assessment of the population structure and geometric distances among all of the accessions in the study (de Sousa et al., 2011). These groupings were entirely consistent with those of the clustering results. It can be concluded that there is a wide genetic base of okra in China and ISSR markers are effective in determining the genetic diversity and relationships among them.

\section{ACKNOWLEDGMENTS}

Research supported by grants from the National Natural Science Foundation of China (\#31071076; \#30871325), Program for New Century Excellent Talents in University (NCET- 
10-0363 to X. Guo), the Excellent Youth Foundation of Hunan Province (\#11JJ1005), the Ph.D. Programs Foundation of Ministry of Education of China (\#20130161110005), International S\&T Cooperation Program of Hunan Province (\#2014WK3012 to J. Ye), Jiangxi Province Science and Technology Support Project (\#20133BBF60080), and the SIT Project of Hunan University, 2013 and 2014.

\section{REFERENCES}

Babaei N, Abdullah NA, Saleh G and Abdullah TL (2012). Isolation and characterization of microsatellite markers and analysis of genetic variability in Curculigo latifolia dryand. Mol. Biol. Rep. 39: 9869-9877.

Calisir S, Ozcan M, Haciseferogullari H and Yildiz MU (2005). A study on some physico-chemical properties of Turkey okra (Hibiscus esculentus L.) seeds. J. Food Eng. 68: 73-78.

de Sousa ACB, Jank L, De Campos T and Sforca DA (2011). Molecular diversity and genetic structure of guineagrass (Panicum maximum Jacq), a tropical pasture grass. Trop. Plant Biol. 4: 185-202.

de Sousa Ferreira Soares G, Assreuy AM, de Almeida Gadelha CA, de Morais Gomes V, et al. (2012). Purification and biological activities of Abelmoschus esculentus seed lectin. Protein J. 31: 674-680.

Earl DA and vonHoldt BM (2012). STRUCTURE HARVESTER: a website and program for visualizing STRUCTURE output and implementing the Evanno method. Conserv. Genet. Resour. 4: 359-361.

Esselman EJ, Li JQ, Crawford DJ, Winduss JL, et al. (1999). Clonal diversity in the rare Calamagrostis porteri ssp. insperata (Poaceae): comparative results for allozymes and random amplified polymorphic DNA (RAPD) and inter simple sequence repeat (ISSR) markers. Mol. Ecol. 8: 443-451.

Evanno G, Regnaut S and Goudet J (2005). Detecting the number of clusters of individuals using the software STRUCTURE: a simulation study. Mol. Ecol. 14: 2611-2620.

Farsani TM, Etemadi N, Sayed-Tabatabaei BE and Talebi M (2012). Assessment of genetic diversity of bermudagrass (Cynodon dactylon) using ISSR markers. Int. J. Mol. Sci. 13: 383-392.

Ford CE (1938). A contribution to a cytogenetical survey of the Malvaceae. Genetica 20: 431-452.

Gul MZ, Bhakshu LM, Ahmad F, Kondapi AK, et al. (2011). Evaluation of Abelmoschus moschatus extracts for antioxidant, free radical scavenging, antimicrobial and antiproliferative activities using in vitro assays. BMC Complement. Altern. Med. 11: 64.

Gupta PK and Varshney RK (2000). The development and use of microsatellite markers for genetic analysis and plant breeding with emphasis on bread wheat. Euphytica 113: 163-185.

Jie W, Xiaobing C, Hualan Y and Guodao L (2008). Okra genomic DNA extraction and identification. Chin. Agric. Sci. Bull. 24: 99-103.

Liu K and Muse SV (2005). PowerMarker: an integrated analysis environment for genetic marker analysis. Bioinformatics 21: 2128-2129.

Mortz E, Krogh TN, Vorum H and Gorg A (2001). Improved silver staining protocols for high sensitivity protein identification using matrix-assisted laser desorption/ionization-time of flight analysis. Proteomics 1: 1359-1363.

Nagl N, Taski-Ajdukovic K, Popovic A and Curcic A (2011). Estimation of genetic variation among related sugar beet genotypes by using RAPD. Genetika 43 : $575-582$.

Oyelade OJ, Ade-Omowaye BIO and Adeomi VF (2003). Influence of variety on protein, fat contents and some physical characteristics of okra seeds. J. Food Eng. 57: 111-114.

Pritchard JK, Stephens M and Donnelly P (2000). Inference of population structure using multilocus genotype data. Genetics 155: 945-959.

Reddy MP, Sarla N and Siddiq EA (2002). Inter simple sequence repeat (ISSR) polymorphism and its application in plant breeding. Euphytica 128: 9-17.

Schafleitner R, Kumar S, Lin CY, Hegde SG, et al. (2013). The okra (Abelmoschus esculentus) transcriptome as a source for gene sequence information and molecular markers for diversity analysis. Gene 517: 27-36.

Sethy NK, Shokeen B, Edwards KJ and Bhatia S (2006). Development of microsatellite markers and analysis of intraspecific genetic variability in chickpea (Cicer arietinum L.). Theor. Appl. Genet. 112: 1416-1428.

Siemonsma JS (1982). West African okra-morphological and cytogenetical indicators for the existence of a natural amphidiploid of Abelmoschus esculentus (L.) and A. manihot (L.) Mediks. Euphytica 31: 241-225.

Vaiman D, Mercier D, Moazami-Goudarzi K, Eggen A, et al. (1994). A set of 99 cattle microsatellites: characterization, synteny mapping, and polymorphism. Mamm. Genome 5: 288-297. 
Wang XM, Hou XQ, Zhang YQ, Yang R, et al. (2012). Genetic diversity of the endemic and medicinally important plant Rheum officinale as revealed by inter-simpe sequence repeat (ISSR) markers. Int. J. Mol. Sci. 13: 3900-3915.

Wei L and Wu XJ (2012). Genetic variation and population differentiation in a medical herb Houttuynia cordata in China revealed by inter-simple sequence repeats (ISSRs). Int. J. Mol. Sci. 13: 8159-8170.

Xie W, Zhang X, Cai H and Liu W (2010). Genetic diversity analysis and transferability of cereal EST-SSR markers to orchardgrass (Dactylis glomerata L.). Biochem. Syst. Ecol. 38: 740-749.

Zane L, Bargelloni L and Patarnello T (2002). Strategies for microsatellite isolation: a review. Mol. Ecol. 11: 1-16.

Zhang F, Ge Y, Wang W, Yu X, et al. (2012). Molecular characterization of cultivated bromeliad accessions with intersimple sequence repeat (ISSR) markers. Int. J. Mol. Sci. 13: 6040-6052. 